\title{
Survey Report on Status Quo and Influencing Factors of Entrepreneurship of New Generations
}

\author{
Dong Yang ${ }^{1, a}$, Xubin $\mathrm{Li}^{2, b}$, Pengcheng Han ${ }^{3, \mathrm{c}}$ and Fengfei $\mathrm{Li}^{4, \mathrm{~d}}$ \\ ${ }^{1}$ Economic and Management Department, Tianjin University of Science \& Technology, Tianjin \\ 300222, China \\ ayilinhrm@126.com, b2401821674@qq.com, c416325745@qq.com, d1225996859@qq.com
}

\begin{abstract}
Keywords: New generations, entrepreneurship, entrepreneur
Abstract. Entrepreneurial desire, self-capacity and professionalism level of new-generations of entrepreneurs are main factors influencing the transition of entrepreneurs from survival to development. Through a series of links including selection of survey subjects, questionnaire design and survey and interview, we had an in-depth understanding of the status quo of entrepreneurship of new generations with focus on analysis of subjective and objective factors influencing the entrepreneurship of new generations, and identified the key points to solve the issues regarding entrepreneurship of new generations based on the characteristics of new generations, i.e. entrepreneurial education, entrepreneurial capacity and improved entrepreneurial environment.
\end{abstract}

\section{Introduction}

In this study, the survey was conducted on the status quo of entrepreneurial practice of new generations in Tianjin, including entrepreneurial practice modes, entrepreneurial practice approaches, and issues regarding entrepreneurial practice, and appropriate establishment of entrepreneurial practice. Through continuous interview and survey, in-depth engagement with individual entrepreneurs, we had a much deeper understanding of the influences of entrepreneurial practice of current new generations on personal development and regional development.

Though ambitious entrepreneurial dreams, new generations of entrepreneurs may be satisfied with the situation and encountered with some obstacles in their early startup or practice stage. It is imperative for the universities and relevant departments to give reasonable suggestions for promoting the entrepreneurship of new generations based on the characteristics of new generations of entrepreneurs [1].

The survey was started from several entrepreneurial cases of new generations and extended with the questionnaire. We summarized main factors affecting the success or failure through case investigation, considered the common characters of new generations, and verified the different situations regarding low success rate of entrepreneurial practice of new generations through investigation.

The survey is designed to enrich the constructive research in terms of entrepreneurial practice theoretically, and benefit the entrepreneur groups of new generations and result in the thinking of relevant entities practically, thus creating an excellent entrepreneurial environment jointly.

\section{Survey Process}

Case Investigation. There are more studies and inclusive studies regarding entrepreneurial practice of new generations based on existing literature studies, but less specialized studies. There are more descriptive studies regarding entrepreneurial cases and practice but less regarding entrepreneurial practice. Starting from the blank field, this study selected express delivery supermarket and group purchase website as our cases.

Following our investigation, the express delivery supermarket was established on campus to address the troubles regarding time, distance and security for students to pick up the parcel at the entrance of the college, which means a great business challenge. Student D was right studying relevant entrepreneurial courses offered by the university, and always understood the entrepreneurial 
policies of the university following participation in the entrepreneurial contest. D had an entrepreneurial concept: firstly, communicate with the university, obtain the powerful support from the university, and successfully obtain the entrepreneurial base; secondly, enroll his/her classmates with the intent to set up the entrepreneurial team; thirdly, develop the entrepreneurial planning and determine the distribution of rights and obligations.

In view of the large market and diligent service, the supermarket quickly won the trust from teachers, students and the express delivery company and established the partnership with a couple of express delivery companies.

The case of group purchase website is about e-commerce entrepreneurship. The entrepreneur A intentionally developed his own entrepreneurial experience in this sector from his freshman year because of his interest in it. He studied relevant course and did various part-time jobs, thus learning some skills in interpersonal communication. Later, he was committed to studying the operations of Jack Ma’s Alibaba. After graduation, he began to implement his entrepreneurial dream. He chose the mode of B2C (business to customer), trying to fill the gap in this type of website. Group purchase website not only saved money for students, but also offered take-away service in the restaurants surrounding the campus. His startup capital came from his family and his solicited investment. However, due to limitation in group purchase and low trust among netizens, the group purchase website failed following a half year's exploration and trial [2,3].

Based on two cases, a successful one and a failed one, our analysis showed that: the success of the express delivery supermarket depended upon effective utilization of the support from the university and did not need capital investment for the sector to avoid financial concerns. However, it still had deficiencies, such as lack of systematic management over the supermarket operations, low financial capacity, lack of technical support, etc, all of which would be adverse to the stability and robustness of the supermarket.

Though being a failure, the group purchase website had some merits, such as personal solicitation for the fund and operating the enterprise through seeking social venture capital. Being innovative, the project combined his specialty with his interest, and had market perspective. The reasons for its failure were summed up as follows: insufficient experience, only theoretical support and less practical experience, resulting in lack of estimate of the obstacles during the entrepreneurship and insufficient mental and response preparation; lack of the power of the entrepreneurial team and limited self-capacity, resulting in failure to address various difficulties in the course of entrepreneurship.

Questionnaire. The questionnaire was designed to understand the entrepreneurial attitude, capacity, obstacles and motives of new generations, analyze the factors influencing the entrepreneurial practice of new generations through investigation.

Selection of the investigation subject: college students and graduated students were enrolled as the investigation subject and individual business entities surrounding the university received the questionnaire and interview randomly. In order to obtain the objective and comprehensive investigation results, the investigation subject came from several disciplines and specialties [4].

With individual college students as our subject, the questionnaire consisted of 20 questions, including general information of each respondent, entrepreneurial desire and attitude, and entrepreneurial environment as well as appropriate recommendations.

\section{Analysis on Results of Case Investigation and Questionnaire}

This study focuses on factors influencing entrepreneurial practice of new generations. Our team divided such factors into subjective factors and objective factors. Subjective factors include:

Entrepreneurial Desire. It can be seen through case investigation and analysis that entrepreneurial awareness is of great significance to the entrepreneurship of new generations. Some entrepreneurs with strong entrepreneurial awareness and firm attitude often dare to meet the challenge and may attempt to execute their entrepreneurial desire during their study or after graduation. Though some may suffer failure, their entrepreneurial desire is their spiritual support for revival. Moreover, failure 
is the mother of the success and the success of re-entrepreneurship is dependent upon the lessons from initial entrepreneurial failure.

In the said cases, whether the result succeeded or failed, they obtained the financial support from various parties by virtue of their firm belief in the course of entrepreneurship, thus promoting the development of the enterprise. It can be understood through interview that most respondents agreed with the entrepreneurship of new generations. However, when they were asked whether they would choose any entrepreneur, they indicated that they had insufficient self-capacity or were waiting for appropriate chances. Meanwhile, we also found that new generations did not have sufficient initiative for entrepreneurship. Most entrepreneurs chose entrepreneurship not based on their entrepreneurial belief, but because they were forced to make entrepreneurship due to various dissatisfaction, that is to say, once they had chance to assume a stable position, they might give up the entrepreneurship[5].

According to questionnaire results, when asked what they think about the entrepreneurship of new generations, 55\% of all respondents gave higher rate of support for the entrepreneurship of new generations and thought that their entrepreneurship had positive effect.

As for the entrepreneurial success rate, $17 \%$ of all respondents thought the probability of success was high while over $50 \%$ of the respondents were not optimistic about it. When asked with respect to the selection of entrepreneurial timing, 61\% indicated that they would not make entrepreneurship during their study or immediately after graduation, which means that they took a wait-and-see attitude to the entrepreneurship and had weak entrepreneurship.

Self-Capacity. Under the guidance of certain entrepreneurial desire, the capacity of the entrepreneur is the key to the success of the entrepreneurship. However, due to the confinement of domestic education mode, new generations have poor entrepreneurial capacity. According to case analysis and questionnaire result, we summarized the issues in the entrepreneurial capacity of new generations as follows:

Insufficient Professional Innovation Capacity. The entrepreneurship of new generations are different from that of other social groups with respect to economy aspect and the weakness in social experience. Therefore, new generations need to make specialized innovation with their knowledge as learned to make up the insufficiency in other aspects.

Insufficient Management Capacity. Organization and management capacity is the necessary condition, but many new generation people often lack of the planning for their own career. They have ambiguous goals and neglect their study. They don't learn their specialized knowledge hard or intent to participate in various activities of social associations, thus leading to lack of practicing of self organization and management capacity. Once they set out for entrepreneurial practice, it is easy for them to get involved in the awkward scenario of being willing but unable to do so.

Insufficient Teamwork Capacity. Teamwork awareness and spirit is an obvious symbol and guarantee for the entrepreneurship of new generations. However, new generation of entrepreneurs tend to be proud, arrogant and overconfident, and cannot assess their own capability properly. When faced with some decision-making issues, they cannot understand the power of teamwork, consider the issues in a considerate manner, or make ends meet due to limited self-capacity.

Insufficient Adaptability. According to current overall social environment and the team survey, the entrepreneurial of new generations is a very painstaking process involving many adverse factors such as fund, experience and capability. It not only requires hardworking and the adaptability of "never give up", but also requires mental adjustment capability, involving daring to meet challenges and being aggressive[6].

Objective Factors. Objective factors affecting the entrepreneurial practice of new generations mainly include entrepreneurial environment. The entrepreneurship of new generations requires the advocate national policy advocacy, financial support and the building of good social climate.

Entrepreneurial policies .In recent years, the government has enacted some preferential policies regarding industry and commerce and taxation for college students, thereby offering some convenience to new generation of entrepreneurs. However, such policies still need to improved with their coverage to be expanded. For instance, the government supports the system building for new generation of entrepreneurs, explores a set of systematic regulations and policies, and guarantees the 
legal environment for the entrepreneurship of new generations.

Social Atmosphere. Currently, there is no strong entrepreneurial climate with the entrepreneurial atmosphere not shaped. This is not only affected by Chinese traditional notions such as honesty and stability, but also derived from a relatively short development of entrepreneurial education in China. For instance, entrepreneurial education on campus mostly focuses on the entrepreneurial competition rather than the building of campus entrepreneurial culture.

Financial and Technical Support .Through survey, we found that the foremost problem that faces new generation of entrepreneurs is the lack of entrepreneurial fund. In addition to poor social climate for entrepreneurship, most enterprises or venture capitals are prudent in supporting new generation of entrepreneurs. According to our survey, the fund of new generation of entrepreneurs mostly comes from their family or friends, including some from social groups without guarantee. Technical support is also encountered with the same problem since technology cannot be improved due to lack of fund.

\section{Recommendations}

As for the implications of this survey to us, there are three key points to address the entrepreneurship of new generations, i.e. entrepreneurial education, entrepreneurial capacity and entrepreneurial environment.

Entrepreneurship Education. Great emphasis that the government has attached to entrepreneurial education of new generations is implemented through the support of higher education institutions, which therefore are obligated to actively respond to the national appeal and clarify the talent development goal regarding entrepreneurial education. Overall, higher education institutions shall shift the development mode focusing on academic capacity.

Based on talent demand in the society and aiming at the society and the market, they shall strengthen the development of entrepreneurial capacity of new generations, and set the goal for fostering the talent equipped with both knowledge and skills. Secondly, higher education institutions shall update their education concept and explore an education mode that is beneficial to the entrepreneurship and employment of new generations with knowledge as the base and capacity as the orientation.

They shall also explore the implementation mechanism of entrepreneurial education from several aspects. The first is to reform the curricular setting. They shall reform traditional teaching contents that lack capacity building, specifically, shift from employment-based education to entrepreneurial education, strengthen the flexibility of all courses, expand education approaches, foster students with comprehensive knowledge structure and give them practice opportunities. The second is to strengthen the faculty building and, based on the policies, encourage the involvement and leadership of teachers with reserved entrepreneurial knowledge in entrepreneurship; they may also engage experienced entrepreneurs or governmental staff to offer to students the entrepreneurial guidance regarding practice and policy at regular intervals.

Finally, they shall pay attention to the building of guarantee mechanism for realization of entrepreneurial education. For example, higher education institutions shall offer assistance to the entrepreneurs in terms of hardware, such as entrepreneurial base and commercial center, etc, or cooperate with the enterprises and act as go-between for entrepreneurs. In addition, the building of service system shall be also included. Employment guidance department of higher education institution shall compile entrepreneurial information and release to students in a timely manner with relevant explanation and instructions.

Entrepreneurship Capacity. Based on description of the said issues regarding self capacity of the entrepreneurs, their capacity needs to be improved through practice. Firstly, the entrepreneurs shall continuously strengthen autonomous learning. They shall not only learn specialized theoretical knowledge, but also discover their own point of interest and potential, based on which they shall conduct expanded learning, thus shaping their own professional quality and giving entrepreneurial confidence.

Autonomous learning includes learning of specialized knowledge, and also involves active participation in entrepreneurial practice, going out of the campus and going into the enterprises, etc, 
thus understanding and learning from the society, enriching their own social knowledge, and grasping certain practice. Secondly, new generation of entrepreneurs shall think actively, and in studying specialized courses or practice, always know themselves intentionally, identify any deficiency and take appropriate measures, including thinking about their own interpersonal communication capacity and innovation awareness, etc. Thereby developing essential capacities for the entrepreneurs, emancipating their thoughts and keeping pace with the times.

Entrepreneurial environment. In view of not so strong entrepreneurial climate in the society, we rooted our idea in how to carry through the entrepreneurial policies under the guidance of the governmental policies.

Firstly, central government and local governments shall strengthen the supervision over the implementation of the entrepreneurial policies and guarantee the transparency and effectiveness in implementing the policies.

Secondly, governments and higher education institutions shall establish a practice platform suitable for the entrepreneurship of new generations, such as national entrepreneurship competition hosted by the country and the college students' established by a higher education institution, to convert the technology into the product.

Finally, local governments shall actively carry through relevant policies and regulations promulgated by the country regarding market environment optimization, market order rectification and support for the entrepreneurship of new generations, thus helping new generations solve the issue regarding entrepreneurial fund. Higher education institutions shall establish the entrepreneurial fund, offer entrepreneurial startup capital, and give play to the capital advantage of the enterprises through cooperation with the enterprises. Governments at various levels shall also enhance the investment in entrepreneurial capital for new generations, offer them credit guarantee loans, reduce registered capital and reduce or remit industrial and commercial administration expenses and taxes, thereby jointly realizing diversified financing channels and improving the success rate of entrepreneurship of new generations.

\section{References}

[1] James E: Economic Growth and the Optimal Level of Entrepreneurship. World Development (2016)

[2] Hou Xueying: Thinking of College Students' Entrepreneurship Education from the Perspective of Internet Entrepreneurship. China Market (2015)

[3] Liu Yan, Wu Xiangwei: Research on the Entrepreneurship Service System of College Students. Modern Business (2015)

[4] Shang Yingmei, Fang Lin: Exploring and analysis of the status of practice of entrepreneurship education in Colleges and universities. Modern development Vol.1 No.1 (2013), p. 43-47

[5] Wu Wei: Multidimensional subjectivity from the perspective of entrepreneurship education of college students facing the predicament and mechanism construction. Modern education and Management Vol.3 No.3 (2015), p.115-118

[6] Chen Long, Zhu Yonghua and Liu Haibo: Evaluation on University Student Entrepreneurship Supporting System. Journal of Wuhan Institute of Technology Vol.6 No.6 (2010), p.50-54 